\title{
Repression of fecundity in the neritic copepod Acartia clausi exposed to the toxic dinoflagellate Alexandrium lusitanicum: relationship between feeding and egg production
}

\author{
Jörg Dutz* \\ Alfred Wegener Institute for Polar and Marine Research, PO Box 120161, D-27515 Bremerhaven, Germany
}

\begin{abstract}
The effect of the saxitoxin-producing dinoflagellate Alexandrium lusitanicum on the reproductive success of the calanoid copepod Acartia clausi was examined in the laboratory. Experiments were carried out to investigate the functional response of feeding and fecundity of copepod females at increasing concentrations $\left(200\right.$ to $1600 \mathrm{\mu g} \mathrm{C} \mathrm{l}^{-1}$ ) of either the toxic A. Jusitanicum or the nontoxic Rhodomonas baltica as food sources. Additional experiments were performed to determine if prolonged exposure to A. lusitanicum affects copepod survival and fecundity. Results demonstrate that $A$. clausi fed on toxic cells at high rates without lethal effects and was able to produce eggs. Survival of females was similar with both diets. Depending on the food source, different functional responses were found. Feeding and fecundity of $A$. clausi on a diet of $R$. baltica followed simultaneously a typical satiation response. Fecundity was high and attained maximal rates of 32 to 36 eggs female $\mathrm{e}^{-1} \mathrm{~d}^{-1}$. In contrast, functional responses of ingestion and fecundity by $A$. clausi fed on $A$. lusitanicum were not closely associated. Whereas feeding rates increased linearily with increasing food concentrations, egg production was limited and stayed constant at 16 to 20 eggs female ${ }^{-1} \mathrm{~d}^{-1}$ over the range of food concentrations offered. The comparison of calculated gross growth efficiencies for females feeding on both algae indicated an inefficient utilization of ingested toxic food. High feeding rates on toxic $A$. lusitanicum suggest that saxitoxins do not act as allelopathic chemicals against grazing in A. clausi. Nevertheless, fecundity was adversely affected. It is suggested that ingested toxins probably interfere with digestive processes or cause an enhanced energy expenditure due to detoxification because copepods could cope with toxic algae. As a result, less energy is available and this might explain the reduced fecundity in females.
\end{abstract}

KEY WORDS: Copepods - Egg production - Toxic dinoflagellates

\section{INTRODUCTION}

Dinoflagellate species of the genus Alexandrium are responsible for the occurrence of paralytic shellfish poisoning (PSP) in a variety of hydrographical regions ranging from temperate to tropical areas (Hallegraeff 1995). More than 20 saxitoxin derivatives that differ in structure and toxicity have been identified as the causative toxins for PSP (Oshima 1995). Their specific significance as compounds of the intermediary metab-

•E-mail: jdutz@awi-bremerhaven.de olism or as secondary metabolites is less understood and several functions have been suggested. Saxitoxins may be important cellular constituents involved in growth and replication (Anderson \& Cheng 1988), may function as N-storage compounds (Plumley 1997) or may act as pheromones (Wyatt \& Jenkinson 1997). Additionally, the production of allelopathic chemicals by dinoflagellates as a potential predator defense mechanism has received great attention because reduced or inhibited grazing due to poisoning could be an important factor in harmful bloom dynamics (Fiedler 1982, Huntley et al. 1986, Smayda 1997). 
Recently, Shaw et al. (1997) showed that soluble saxitoxins were perceived by copepods and suggested that they may act as feeding deterrents. However, evidence that saxitoxins or other phycotoxins act as antipredator compounds is less conclusive because feeding interactions between toxic algae and copepods are highly variable and a feeding reduction occurred not exclusively in copepods exposed to algae known to produce phycotoxins (reviewed in Tumer \& Tester 1997). For instance, toxic strains of Alexandrium were rejected by copepods (Huntley et al. 1986, Turriff et al. 1995) or ingested at lower rates in response to increasing toxicity (Ives 1985, 1987). On the other hand, Teegarden \& Cembella (1996) found similar high feeding rates in 2 copepod species exposed to toxic and nontoxic Alexandrium strains. Regardless of the level of feeding on toxic algae, the accumulation of saxitoxins in zooplankton upon exposure to toxic algae and the importance of transfer of toxins by zooplankton in the food web are well documented (White 1981, Turriff et al. 1995, Teegarden \& Cembella 1996).

Apart from variable grazing interactions between Alexandrium spp. and zooplankton, toxic strains may have significant impacts on their consumers, as shown by high mortality rates of fish larvae (Gosselin et al. 1989, Robineau et al. 1991). Although enhanced mortality has been demonstrated for Euterpina acutifrons (Bagøien et al. 1996), copepods appear to be less sensitive or even unaffected (Ives 1987. Turriff et al. 1995, Teegarden \& Cembella 1996). However, the potential effects of feeding on toxic algae or of toxin accumulation on copepod fecundity have received little attention. A single report by Gill \& Harris (1987) demonstrated that Alexandrium tamarense did not support egg production in 2 species of copepods. Most other knowledge of the influence of toxic algae on fecundity is based on non-PSP-producing algae. In experiments performed with monocultures of ichthyotoxic Prymnesiophyceae, Raphidophyceae and Dinophyceae, egg production of several copepods was significantly reduced (Nielsen et al. 1990, Uye \& Takamatsu 1990, Nejstgaard \& Solberg 1996, Turner et al. 1998). From these investigations it appears that the depression of egg production is strongly correlated with a reduction in ingestion rates, which suggests that the level of feeding on Alexandrium spp. could be a primary factor determining copepod fecundity when exposed to dinoflagellates producing saxitoxins.

The specific objective of the present study was to investigate the effects of the toxic dinoflagellate Alexandrium Iusitanicum on the reproductive success of Acartia clausi, a common calanoid copepod of the North Sea (Fransz et al. 1991). Experiments were carried out with focus on the functional response of feeding and fecundity of females in relation to increasing concentrations of toxic $A$. Iusitanicum and the nontoxic cryptophycean Rhodomonas baltica. Results of experiments conducted to investigate influences of prolonged exposure to toxic algae on egg production and survival are also reported

\section{MATERIAL AND METHODS}

Phytoplankton culture. Alexandrium lusitanicum, clone BAH-ME 91, was obtained from the Biologische Anstalt Helgoland located at List/Sylt (Germany). Cultures were kept in 1 to 31 flasks containing TLMedium (Larsen et al. 1994) in seawater of $30 \%$ salinity and exposed to a $16 \mathrm{~h}$ light: $8 \mathrm{~h}$ dark irradiance cycle of $85 \mu \mathrm{E} \mathrm{m}^{-2} \mathrm{~s}^{-1}$. Algae were maintained at $15^{\circ} \mathrm{C}$ in a temperature controlled walk-in chamber. Culture conditions for Rhodomonas baltica were similar except for an irradiance of $120 \mu \mathrm{E} \mathrm{m}^{-2} \mathrm{~s}^{-1}$. The carbon and nitrogen content of both species was determined from subsamples of exponentially growing cultures, filtered on precombusted GF/C filters at low pressure, dried at $60^{\circ} \mathrm{C}$ and combusted in a Carlo Erba Nitrogen Analyzer Model 1500. Cell carbon and nitrogen were calculated by counts of triplicate subsamples on a Coulter Multisizer II model equipped with a $100 \mu \mathrm{m}$ orifice. Because both species differ in size and carbon and nitrogen content (Table 1), experimental food concentrations were based on cell carbon concentration in order to facilitate comparison between algae. Only exponentially growing cultures were used in experiments. Variations in the toxicity of several Alexandrium strains occur during growth in batch cultures, with higher toxicities observed in the exponential growth phase (Boyer et al. 1987. Anderson et al. 1990). For this reason $A$. lusitanicum batch cultures were grown to a concentration of approximately 2000 cells

Table 1. Equivalent spherical diameter (ESD) measured by a Coulter Counter, carbon and nitrogen content and weight ratio of carbon to nitrogen $\left(\mathrm{C}: \mathrm{N}\right.$ ) of algae used in experiments (mean $\pm \mathrm{SD}_{i} \mathrm{n}=$ number of $\mathrm{C} / \mathrm{N}$ determinations)

\begin{tabular}{|c|c|c|c|c|c|}
\hline Species & $\operatorname{ESD}(\mu \mathrm{m})$ & $C \operatorname{cell}^{-1}(\mathrm{pg})$ & $\mathrm{N}_{\text {cell }}^{-1}(\mathrm{pg})$ & $C: N$ & $\mathrm{n}$ \\
\hline Alexandrium lusitanicum & 19.36 & $1005.1 \pm 18.8$ & $205.1 \pm 1.85$ & $4.9 \pm 0.1$ & 4 \\
\hline Rhodomonas baltica & 6.62 & $52.9 \pm 1.8$ & $11.5 \pm 0.4$ & $4.6 \pm 0.1$ & 5 \\
\hline
\end{tabular}


$\mathrm{ml}^{-1}$ in order to minimize possible effects of varying toxicities on Acartia clausi. At this growth stage, toxin content of $A$. lusitanicum was determined by HPLC to vary between 1.25 and $1.56 \mathrm{pg}$ saxitoxin $_{\text {eq }}$ cell $^{-1}$ (Dutz et al. unpubl.). The toxin profile was dominated by the gonyautoxins GTX 1, $4(74 \%)$ followed by GTX 2, 3 (24\%); only gonyautoxins were recorded.

Copepods. Females used in experiments were taken from a culture maintained at the institute to provide a continuous supply of organisms. Acartia clausi cultures were initiated from copepods collected in the German Bight near Helgoland in March 1996. Culture conditions were the same as for the algae except that copepods were kept at an irradiance of 3 to $11 \mu \mathrm{E} \mathrm{m} \mathrm{m}^{-2} \mathrm{~s}^{-1}$. The culture was maintained in $1350 \mathrm{ml}$ glass bottles fixed onto a plankton wheel. Copepods were fed a diet of Rhodomonas baltica at satiation levels. The culture was well established before starting the experiments and several generations were obtained by incubating freshly produced eggs. Experiments were performed between October 1996 and March 1997.

Functional response to increasing concentrations. Experiments were conducted to determine the feeding and egg production response of Acartia clausi to concentrations of both algae ranging from 200 to $1600 \mu \mathrm{g} \mathrm{C} \mathrm{l}^{-1}$. Food suspensions for estimations of feeding rates were prepared by diluting batch cultures with appropriate amounts of algal growth medium to prevent nutrient limitation of algal growth during incubation

Adult females for feeding experiments were selected from the continuous culture and pipetted into $625 \mathrm{ml}$ Duran bottles containing the food suspensions. Following a $24 \mathrm{~h}$ acclimatization period, females were transferred into new bottles containing the same algal suspension as before and experiments were run for additional $24 \mathrm{~h}$. Bottles were carefully closed to prevent any air bubbles and placed onto a plankton wheel $(40 \mathrm{~cm}$ diameter, $1.5 \mathrm{rpm})$ to maintain uniform cell distributions. For each food concentration, 3 experimental bottles containing 10 females each and 3 control bottles without copepods were run simultanously. Cell concentrations were measured from triplicate $100 \mathrm{ml}$ subsamples preserved in Lugol's solution before and after the experimental procedure by counts on a Coulter Counter. In the case of Rhodomonas baltica, subsamples were immediately counted because fixation artifacts occurred as described by Klein Breteler (1985). However, repeated tests showed that counts of living and fixed cells were constant for $1 \mathrm{~h}$. Rates of ingestion were calculated by applying formulas given by Frost (1972). Total particle reduction in experimental bottles decreased from on average 25 to $7 \%$ and 10 to $5 \%$ with increasing food concentration of Alexandrium lusitanicum and $R$. baltica, respectively.

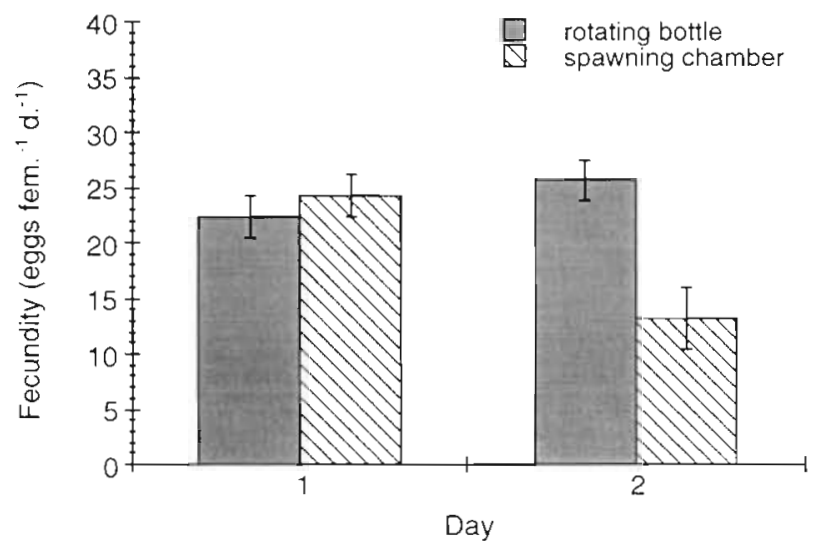

Fig. 1. Acartia clausi. Daily egg production of females obtained by 2 incubation methods. Females were fed Rhodomonas baltica at $600 \mu \mathrm{g} \mathrm{C} \mathrm{l}^{-1}$ Vertical bars indicate standard error of the mean

Egg production rates of females fed each phytoplankton species were examined by incubating 5 females in each of 3 experimental bottles. The experimental procedure was the same as in the ingestion experiments. In a previous experiment differences in egg production rates obtained by 2 methods were tested. Five females were incubated in each of 3 rotating $625 \mathrm{ml}$ screw-cap bottles or 3 commonly used spawning chambers (volume of spawning chamber = $700 \mathrm{ml}$ ) equipped with a bottom of $100 \mu \mathrm{m}$ mesh gauze in order to prevent copepods feeding on their eggs (Fig. 1). Results revealed no significant differences for the first day (2-tailed $t$-test, $t_{\mathrm{s}}=-0.85$, Sokal \& Rohlf 1995). Instead, after the second day of incubation the number of eggs produced in the spawning chamber was lower than in the bottle treatment due to sedimentation of food particles at the bottom of the chamber. Additionally, death of females was observed in spawning chambers because they were trapped between the meshes. Therefore it was decided to incubate females in rotating bottles as a standard procedure. After an acclimatization period of $24 \mathrm{~h}$, experiments were run for $24 \mathrm{~h}$. Females were removed from the bottles. Eggs laid were concentrated on $20 \mu \mathrm{m}$ mesh gauze, transferred to petri dishes and counted under a dissecting microscope at $66 \times$ magnification. Empty egg shells were included in the counts, but they rarely contributed more than $2 \%$ of the total egg number.

Upon termination of feeding and egg production experiments, females were anaesthetized with MS 222 and their prosome length was measured under an inverted microscope at $100 \times$ magnification. After recovery in filtered seawater, groups of 30 to 40 females of known length were pooled on a precombusted $\mathrm{GF} / \mathrm{C}$ filter $\left(500^{\circ} \mathrm{C}, 4 \mathrm{~h}\right)$ and dried at $60^{\circ} \mathrm{C}$. The carbon and nitrogen content was determined and 
length-weight factors for females of $5.6 \pm 0.52 \mu \mathrm{g} \mathrm{C}$ $\mathrm{mm}^{-1}$ and of $1.4 \pm 0.13 \mu \mathrm{g} \mathrm{N} \mathrm{mm} \mathrm{Nm}^{-1}(\mathrm{C}: \mathrm{N}=4.1 \pm 0.05$, mean weight $=4.8 \pm 0.58 \mu \mathrm{g} \mathrm{C}$ female ${ }^{-1}, \mathrm{n}=7$ ) were established in order to calculate the gross growth efficiency of egg production of Acartia clausi feeding on both algae.

Long-term egg production and survival. Two experimental setups were designed to examine the effect of long-term exposure of copepods to toxic Alexandrium lusitanicum. First, an experiment was performed to test if A. lusitanicum affects survival of Acartia clausi. Females, sorted out of a cohort of copepods that had freshly moulted, were incubated in $625 \mathrm{ml}$ screw-cap bottles containing food concentrations at satiation levels of $1200 \mu \mathrm{g} \mathrm{C} \mathrm{^{-1 }}$ of either $A$. lusitanicum or Rhodomonas baltica. Five females were added to each of triplicate experimental bottles. Every 3 to $4 \mathrm{~d}$, food suspensions were exchanged and restored to initial concentrations. Alternatively, females were transferred to new bottles to prevent accumulation of eggs. Copepods were checked for physiological condition daily and assigned to 1 of 3 catagories (sensu Teegarden \& Cembella 1996): healthy, impaired or dead. If necessary, dead females were removed and the experiment continued until the last copepod died.

In a second experiment, egg production was monitored over a period of $9 \mathrm{~d}$ to investigate if prolonged exposure of females to toxic Alexandrium lusitanicum resulted in changes in egg production rates compared to short-term experiments. Five females were incubated in triplicate experimental bottles at $1000 \mu \mathrm{g} \mathrm{Cl}^{-1}$ of each algae. Every day females were pipetted into new bottles containing the identical food suspensions. Their physiological condition and egg production were checked as described above. After $6 \mathrm{~d}$, food conditions were switched and females kept in $A$. Iusitanicum were transferred to bottles containing $R$. baltica as food and vice versa. Incubation continued for 3 more days.

\section{RESULTS}

\section{Functional response to increasing concentrations}

Feeding rates of Acartia clausi observed in response to increasing food concentrations of Alexandrium lusitanicum and Rhodomonas baltica revealed that females actively preyed upon $A$. Iusitanicum in unialgal treatments and did not avoid ingestion of toxic cells. Both algae were ingested at rates proportional to their abundance (Fig. 2). However, the functional response to increasing particle concentrations differed between the food treatments. For females feeding on $R$. baltica, ingestion rate satiated at food concentrations of $1200 \mu \mathrm{g} \mathrm{C} \mathrm{l}^{-1}$. Maximum daily ingestion was

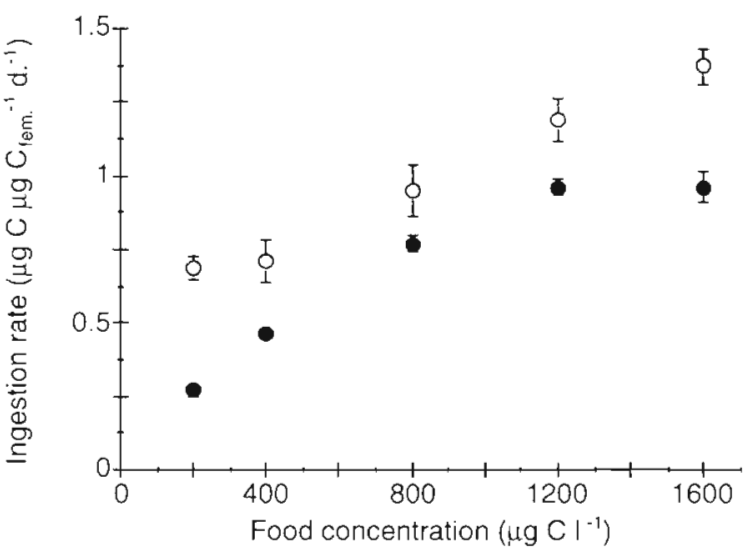

Fig. 2. Acartia clausi. Ingestion rates of females as a function of food carbon concentration of either Alexandrium lusitanicum $(O)$ or Rhodomonas baltica ( ). Vertical bars indicate standard error of the mean

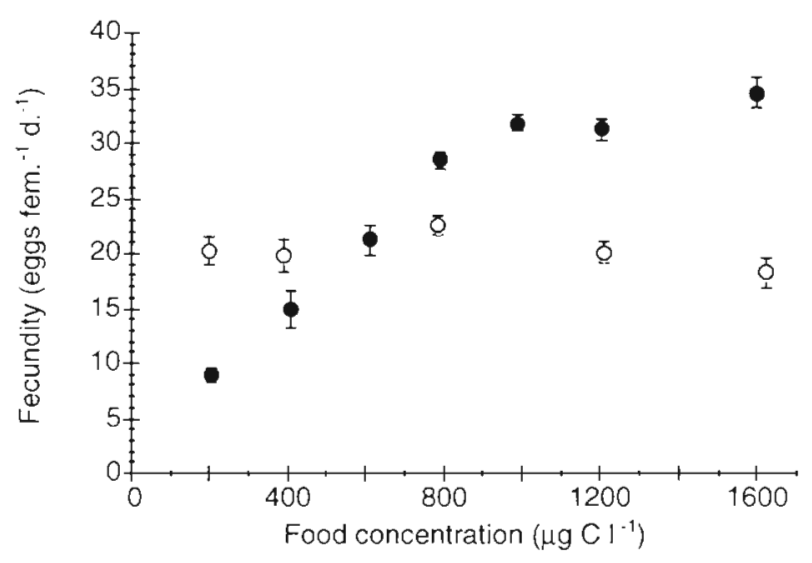

Fig. 3. Acartia clausi. Daily egg production of females as a function of food carbon concentration of either Alexandrium Jusitanicum (0) or Rhodomonas baltica ( ). Vertical bars indicate standard error of the mean

$0.96 \mu \mathrm{g} \mathrm{C} \mu \mathrm{C}_{\text {female }}{ }^{-1} \mathrm{~d}^{-1}$ and similar at 1200 and 1600 $\mu \mathrm{C} \mathrm{Cl}^{-1}$ In contrast, ingestion rates of females feeding on A. lusitanicum increased progressively with increasing amounts of food and did not appear to satiate over the range of concentrations examined. Generally, A. clausi preyed on A. lusitanicum at higher rates than on $R$. baltica. A maximum ingestion of $1.37 \mu \mathrm{g} \mathrm{C}$ $\mu \mathrm{g} \mathrm{C}_{\text {female }}{ }^{-1} \mathrm{~d}^{-1}$ was attained at $1600 \mu \mathrm{g} \mathrm{C} \mathrm{\textrm {I } ^ { - 1 }}$ Thus, maximal ingestion rates exceeded those observed with $R$. baltica as food by more than one third.

Egg production by Acartia clausi fed on Rhodomonas baltica exhibited a functional response to increasing food concentrations similar to that observed in feeding experiments (Fig. 3). Mean egg production rates satiated at $1000 \mu \mathrm{g} \mathrm{Cl}^{-1}$ when 32 eggs female ${ }^{-1} \mathrm{~d}^{-1}$ were produced and remained constant with further in- 
Table 2. Acartia clausi. Carbon and nitrogen budget for copepods feeding on Rhodomonas baltica and Alexandrium lusitanicum. GGE: gross growth efficiency of egg production. See text for further explanations

\begin{tabular}{|c|c|c|c|c|c|c|c|}
\hline \multirow[t]{2}{*}{ Species } & \multirow{2}{*}{$\begin{array}{l}\text { Food conc. } \\
\left(\mu \mathrm{g} \mathrm{Cl}^{-1}\right)\end{array}$} & \multicolumn{2}{|c|}{ Ingestion (I) } & \multicolumn{2}{|c|}{ Egg production (E) } & \multicolumn{2}{|c|}{$G G E=E / 1$} \\
\hline & & $\begin{array}{c}\left(\mu g C \mathrm{Cg}^{-1}\right. \\
\left.\mathrm{C} \mathrm{d}^{-1}\right)\end{array}$ & $\begin{array}{c}\left(\mu g N \mu g^{-1}\right. \\
\left.N d^{-1}\right)\end{array}$ & $\begin{array}{c}\left(\mu g C \mu g^{-1}\right. \\
\left.C d^{-1}\right)\end{array}$ & $\begin{array}{c}\left(\mu g N \mu g^{-1}\right. \\
\left.N d^{-1}\right)\end{array}$ & $\mathrm{C}$ & $\mathrm{N}$ \\
\hline \multirow{5}{*}{ Rhodomonas baltica } & 200 & 0.27 & 0.24 & 0.07 & 0.06 & 0.27 & 0.24 \\
\hline & 400 & 0.46 & 0.41 & 0.12 & 0.10 & 0.26 & 0.24 \\
\hline & 800 & 0.77 & 0.69 & 0.22 & 0.18 & 0.28 & 0.26 \\
\hline & 1200 & 0.96 & 0.86 & 0.25 & 0.21 & 0.27 & 0.24 \\
\hline & 1600 & 0.96 & 0.86 & 0.26 & 0.21 & 0.27 & 0.25 \\
\hline \multirow[t]{5}{*}{ Alexandrium Iusitanicum } & 200 & 0.69 & 0.58 & 0.16 & 0.13 & 0.23 & 0.22 \\
\hline & 400 & 0.71 & 0.59 & 0.15 & 0.12 & 0.21 & 0.21 \\
\hline & 800 & 0.95 & 0.79 & 0.17 & 0.14 & 0.18 & 0.18 \\
\hline & 1200 & 1.19 & 1.00 & 0.16 & 0.13 & 0.14 & 0.13 \\
\hline & 1600 & 1.37 & 1.15 & 0.14 & 0.12 & 0.10 & 0.10 \\
\hline
\end{tabular}

creases in food concentration. Results obtained in experiments with Alexandrium lusitanicum as a food organism demonstrate that females were able to produce eggs on a diet of toxic algae. Egg production rates of less than 1 egg $\mathrm{d}^{-1}$ by females incubated without food under similar conditions (results not shown) indicate that fecundity depended on ingested $A$. lusitanicum and not on stored energy. However, in contrast to the functional response shown by females exposed to $R$. baltica, daily egg production did not increase in response to increasing amounts of $A$. Iusitanicum offered. Eggs were produced at similar rates of 16 to 24 eggs female ${ }^{-1} \mathrm{~d}^{-1}$ and were not significantly different between treatments (single classification ANOVA, $F_{4,10}=2.72, \mathrm{p}>0.05$, Sokal \& Rohlf 1995).

Weight-specific egg production rates in terms of carbon and nitrogen were calculated from mean rates obtained in experiments in order to estimate gross growth efficiencies of egg production of Acartia clausi exposed to varying concentrations of both algae (Table 2). Mean numbers of eggs produced were converted to carbon applying an average egg weight of $0.036 \mu \mathrm{g}$ given for $A$. clausi by Kiørboe \& Sabatini (1995). Nitrogen was calculated assuming a C:N ratio of 5.05 as determined for Acartia tonsa eggs (Kiørboe et al. 1985). Since Alexandrium lusitanicum and Rhodomonas baltica had corresponding $\mathrm{C}: \mathrm{N}$ ratios (Table 1), the relationship of ingestion rates calculated in terms of carbon and nitrogen is similar for both algae.

In experiments performed with Rhodomonas baltica as food, specific ingestion rates of carbon and nitrogen varied in a manner similar to specific egg production rates. Thus, females of Acartia clausi converted ingested food into eggs at nearly constant efficiencies of 0.26 to 0.28 for carbon and 0.24 to 0.26 for nitrogen. In contrast, gross growth efficiencies of females exposed to Alexandrium lusitanicum decreased with increasing food concentration from 0.23 for carbon and 0.22 for nitrogen at $200 \mu \mathrm{g} \mathrm{Cl}^{-1}$ to 0.10 for both carbon and nitrogen at $1600 \mu \mathrm{g} \mathrm{Cl}^{-1}$. Because egg production remained constant over the range of concentrations examined, females of $A$. clausi were apparently unable to convert the amount of food ingested in excess of the rate observed at $200 \mu \mathrm{g} \mathrm{C} \mathrm{I}^{-1}$ into eggs resulting in a linear decrease of the gross growth efficiency (Fig. 4). The regression of efficiencies in dependence of food concentration yields statistically significant results for carbon (ANOVA, $F_{1,3}=308, \mathrm{p}<0.001$, Sokal \& Rohlf 1995) and nitrogen (data not shown). Even at low food concentrations, females did not attain the efficiency observed with $R$. baltica despite a higher number of eggs produced at 200 and $400 \mu \mathrm{g} \mathrm{C}^{-1}$. Apparently, $A$. lusitanicum did not favor high egg production in $A$. clausi.

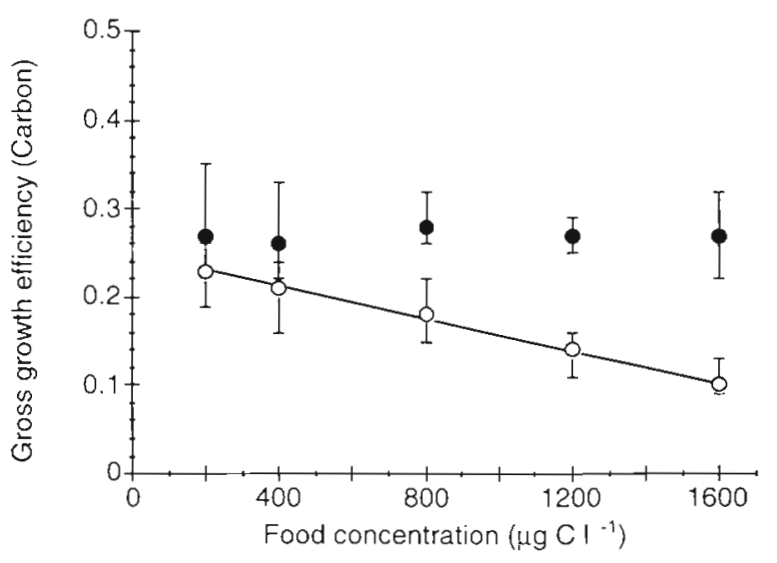

Fig. 4. Acartia clausi. Relationship between calculated gross growth efficiencies in terms of carbon and food carbon concentrations for females feeding on either Alexandrium lusitanicum (0) or Rhodomonas baltica ( ). Vertical bars indicate maximum and minimum estimates. (Regression is: $b=-9.5 \mathrm{e}^{-0.5}, a=0.25, \mathrm{r}^{2}=0.79$ ) 


\section{Long-term experiments}

Results of the effects of prolonged exposure on the fecundity of Acartia clausi revealed that females were able to sustain egg production on a diet of toxic Alexandrium lusitanicum for several days (Fig. 5). However, the lower reproductive response observed in females exposed to A. lusitanicum resembled that obtained in short-term experiments and persisted during the 6 following days of incubation. Daily fecundity of females on a diet of toxic $A$. Iusitanicum was on average $30 \%$ lower than that on non-toxic Rhodomonas baltica. Initial egg production rates by females feeding on $R$. baltica increased from 32 to 38 eggs female ${ }^{-1} \mathrm{~d}^{-1}$ and stayed constant with further incubation. A similar pattern of daily fecundity occurred in copepods kept in A. lusitanicum suspensions, but mean number of eggs produced increased more slowly from initially 22 eggs female $\mathrm{f}^{-1} \mathrm{~d}^{-1}$ to 29 eggs female ${ }^{-1} \mathrm{~d}^{-1}$ on the fifth day, indicating that an equilibrium was achieved with delay. Upon exchange of the diet following Day 6 of incubation, daily fecundity of females acclimated on $R$, baltica declined rapidly to 26 eggs female ${ }^{-1} \mathrm{~d}^{-1}$ on Day 8 , a rate that is representative of females reared on A. lusitanicum in the first part of the experiment. Conversely, females acclimatized to A. lusitanicum were not able to increase their egg production when fed with $R$. baltica at satiating levels and produced eggs at more or less constant rates of 24 to 29 eggs female ${ }^{-1} \mathrm{~d}^{-1}$ on 3 consecutive days. These results suggest that toxic $A$. lusitanicum affect egg production of $A$. clausi beyond direct exposure and recovery may take longer than the $3 \mathrm{~d}$ of observations.

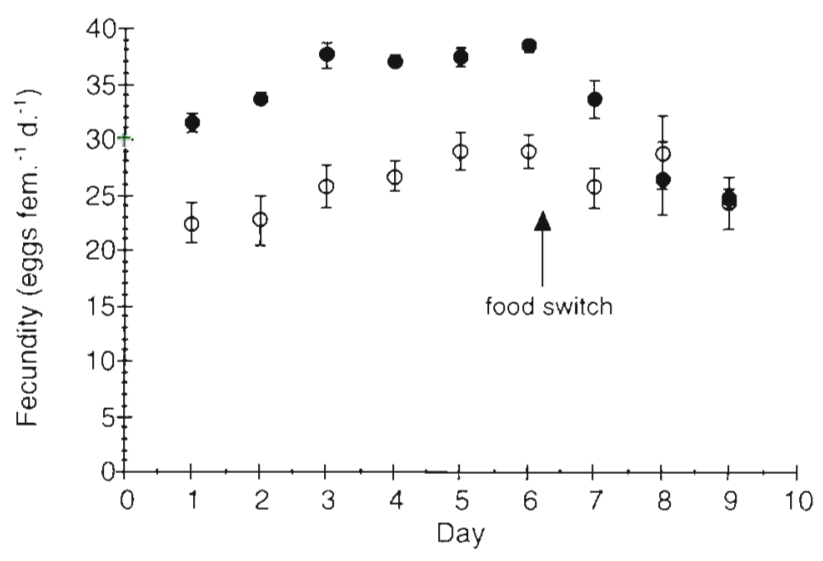

Fig. 5. Acartia clausi. Daily variations in fecundity of females fed either Alexandrium lusitanicum (0) or Rhodomonas baltica (-) at satiation levels. On Day 6 of the incubation, food type was exchanged between treatments. For clearness symbols continue. Vertical bars indicate standard error of the mean

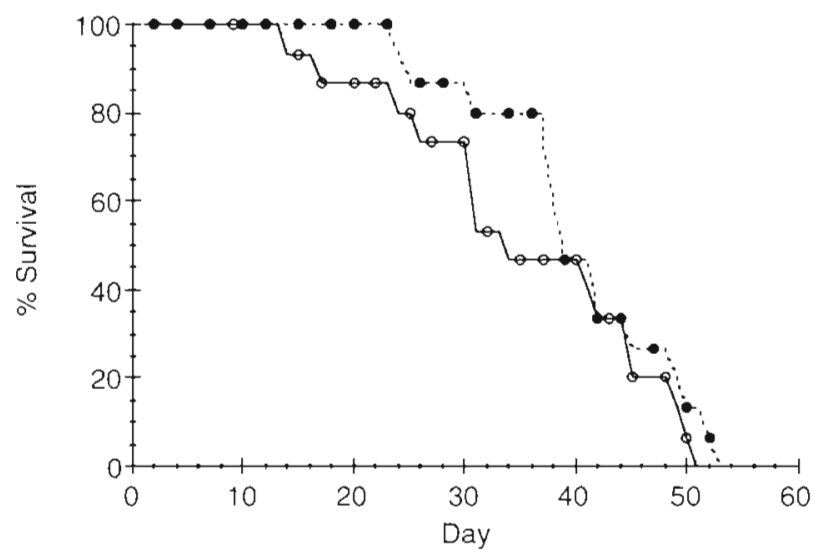

Fig. 6. Acartia clausi. Survival curves of females fed either Alexandrium lusitanicum (O) or Rhodomonas baltica (-) at satiation levels. Not all data points are shown

Survival of female Acartia clausi fed both algae at satiation concentrations was generally high during the initial 2 wk of incubation (Fig. 6). In experiments performed with a diet of Alexandrium lusitanicum the first female died on Day 14, followed by a steady decrease in cumulative survival until the last female died on Day 51. Survival of copepods feeding on Rhodomonas baltica appeared to be higher during the initial phase of the experiment. No mortality occurred during the first 3 wk. Cumulative survival began to decrease slowly from $100 \%$ on Day 24 to $80 \%$ on Day 38 followed by a sharp increase in mortality. Median survival time of $39 \mathrm{~d}$ of females feeding on $R$. baltica did not differ significanty from median survival of $35 \mathrm{~d}$ shown by females reared on A. Iusitanicum (MannWhitney $U$-test, 2 -tailed, $U_{\mathrm{s}}=111$, Sokal \& Rohlf 1995).

Changes observed in the physiological condition of females exposed to Alexandrium Iusitanicum followed the same temporal pattern in both the survival and the long-term egg production experiment and were therefore summarized (Fig 7). Results shown for the first $48 \mathrm{~h}$ of incubation were also representative for observations made in short-term feeding and egg production experiments. Death of females was rare; most of the females appeared healthy subsequent to the acclimatization period. Impaired females contributed one third of total females after $24 \mathrm{~h}$. Typically, they were lethargic and displayed a reduced pipette avoidance behaviour as described for Acartia hudsonica by Ives (1985). Examination of these females under the dissecting microscope revealed an unusual trembling of the first antennae and uncoordinated appendage movements that may indicate a loss of neuromuscular control due to accumulated toxins. However, a constant feature observed throughout the experiments was that impairment of copepods decreased with fur- 


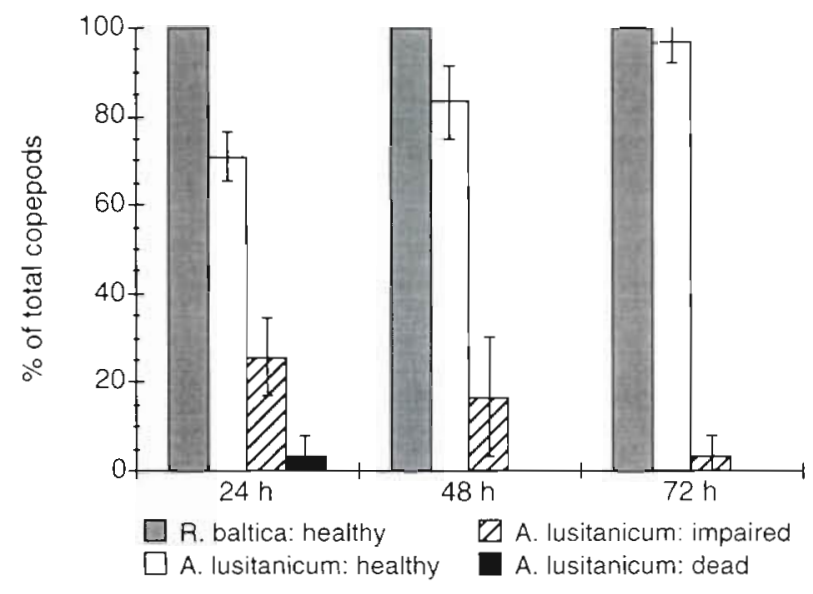

Fig. 7. Acartia clausi. Physiological condition of females feeding on either A. lusitanicum or $R$. baltica for 24,48 and 72 h at satiation levels. Vertical bars indicate standard error of the mean

ther incubation to $4 \%$ of total copepods after $3 \mathrm{~d}$ of exposure to A. lusitanicum. Upon further incubation all of the copepods appeared healthy as observed in experiments conducted with Rhodomonas baltica as food, but impairment occurred irregularly from time to time (data not shown).

\section{DISCUSSION}

The present study reveals that Acartia clausi fed on Alexandrium lusitanicum without lethal implications. Ingestion of toxic cells by females was accompanied by short-term impairment, but adverse effects ceased on further incubation and did not result in reduced survival in comparison to high quality food. Ingestion rates obtained in feeding experiments were generally high and similar to rates reported for certain species of Acartia feeding on non-toxic dinoflagellates (Ives 1985, Stoecker \& Sanders 1985, Kleppel \& Burkart 1995). Several other studies have been conducted to understand feeding responses of copepods to toxic Alexandrium spp. Results have demonstrated not only behavioural rejection of algae or reduced grazing but also high ingestion rates (Ives 1985, Huntley et al. 1986, Turriff et al. 1995, Teegarden \& Cembella 1996) which questions the potential significance of saxitoxins in controlling grazer interactions between toxic Alexandrium spp. and copepods.

It has been suggested that behavioural rejection prior to ingestion or an adverse physiological reaction to ingested phycotoxins accounts for the observed suppression of feeding rates (Huntley et al. 1986, Ives 1987, Turriff et al. 1995). In most of these investigations conclusions have been derived from short-term incu- bation experiments. For instance, Ives (1985, 1987) conducted experiments of 4 to $8 \mathrm{~h}$ without prior acclimatization of copepods to toxic strains of Alexandrium tamarense. From observations of copepod paralysis and decreasing ingestion rates with increasing toxicity of strains he concluded that copepods suffered from progressive physiological incapacitation which interfered with coordinated appendage movements and cell capture abilities. Similar adverse effects of $A$. lusitanicum on Acartia clausi were recorded in the present study. However, the observed recovery on further incubation strongly suggests that females were able to cope with ingested toxins. Therefore, the incubation time in experiments performed by Ives (1985, 1987) may have been too short for copepods to become accustomed to toxins. This in turn would lead to the observed reduction in feeding rates. Conversely, in other short-term experiments interspecific differences were found in feeding responses to toxic Alexandrium spp., with high and unaffected feeding rates in one species in comparison to the other (Huntley et al. 1986, Teegarden \& Cembella 1996). The differences have been attributed to a diel feeding rhythm or speciesspecific rejection behaviour. Alternatively, these results may indicate that different abilities of species to cope with ingested toxins account for variable initial feeding responses observed in copepods. The present results suggest that short-term experiments should be interpreted with caution with respect to feeding behaviour.

Physiological implications of toxins could be of minor influence in determining feeding interactions because the significance of saxitoxins as antipredator compounds is doubtful. The present results provide no evidence for a reduced feeding on toxic cells (Huntley et al. 1986, Turriff et al. 1995). High feeding rates on. Alexandrium lusitanicum by Acartia clausi generally support the conclusion of Teegarden \& Cembella (1996) that saxitoxins are not crucial in determining feeding interactions between toxic Alexandrium spp. and copepods. Additionally, studies demonstrating behavioural rejection of Alexandrium spp. found no convincing evidence that saxitoxins were responsible for the observed feeding inhibition and hypothesized that other bioactive compounds induce avoidance behaviour in copepods (Huntley et al. 1986, Turriff et al. 1995). Similarly, in a recent study enhanced mortality observed in Euterpina acutifrons exposed to toxic A. minutum has been supposed to be related to toxins other than PSP that account for haemolytic activity (Bagøien et al. 1996). Because several non-toxic dinoflagellates were rejected by copepods as well (see Turner \& Tester 1997), one might speculate that they share a common allelopathic chemical with some Alexandrium species or, alternatively, that distinct 
compounds act as antipredator mechanisms. As most of the studies investigating feeding responses of copepods used different strains of Alexandrium, the role of saxitoxins or other compounds in guiding species-specific interactions and the ability of copepods to cope with them remain unresolved.

In addition to toxicity or other bioactive chemical compounds, Turner \& Tester (1997) suggested that a lack of co-evolutionary experience in dealing with toxins might also be responsible for observed rejection of toxic cells by copepods. The present results demonstrate that this is not necessarily the case. Although no toxic blooms of Alexandrium Iusitanicum or other PSPproducing dinoflagellates have been recorded from the German Bight, females of Acartia clausi ingested A. lusitanicum and apparently were able to cope with toxins without any prior experience. Interestingly, only some females were adversely affected subsequent to ingestion of toxic cells, indicating that intraspecific differences also exist in copepods.

The divergent responses in feeding and fecundity of females in relation to increasing food quantities of both algae afford further insights into the interaction of toxic Alexandrium and Acartia. The limited fecundity on a diet of Alexandrium lusitanicum, contrasting with high and constantly increasing ingestion rates over the range of concentrations considered, indicates that the reduced egg production is associated with ingestion of toxic cells. A reduced fecundity in response to feeding on Alexandrium tamarense was also demonstrated for Calanus helgolandicus by Gill \& Harris (1987). Thus, results contrast with previous investigations on the impact of algae producing toxins other than saxitoxin, which revealed that suppressed fecundity resulted from feeding avoidance of these algae (Nielsen et al. 1990, Uye \& Takamatsu 1990, Nejstgaard \& Solberg 1996, Turner et al. 1998).

Apart from several environmental factors such as temperature or salinity that influence feeding or fecundity in copepods (Uye 1981, Stearns et al. 1989) and have been kept constant in the present study, the coherence of feeding and fecundity depends largely on food concentration and food quality. Algal species as well as their size, shape and nutritional composition are considered as important attributes of food quality that determine functional responses of copepods (Libourel Houde \& Roman 1987, Støttrup \& Jensen 1990, Jónasdóttir 1994). Size and shape likely influenced results obtained in the present study because food sources differed greatly in size and particle capture efficiency of Acartia spp. increases with increasing particle size up to an optimum food diameter (Nival \& Nival 1976, Berggreen et al. 1988, Stóttrup \& Jensen 1990). Alexandrium Iusitanicum fits well into the optimum particle size of 15 to $50 \mu \mathrm{m}$ reported for Acartia clausi (Nival \&
Nival 1976). Therefore, enhanced capture efficiency for A. Iusitanicum explains the higher feeding rates and also higher fecundity at low food concentrations in contrast to the smaller Rhodomonas baltica. However, this cannot account for the observed divergent responses in feeding and fecundity observed on a diet of A. lusitanicum. Instead, estimated gross growth efficiencies indicate that even at low food concentrations the ingested amount of $A$. lusitanicum is less efficiently converted into eggs than ingested $R$. baltica. Thus, $A$. lusitanicum may be less nutritious for copepods.

Several studies have emphasized the importance of food biochemical composition in copepod nutrition (see Ianora 1998 for review). Variable algal nitrogen. contents generated different responses in egg production rates of copepods (Checkley 1980, Kiørboe 1989), but likely did not contribute to lower efficiencies because the amount of nitrogen ingested by Acartia clausi feeding on Alexandrium lusitanicum was higher than on Rhodomonas baltica. Although some specific nutrients or trace substances required for high reproductive success may be lacking in A. lusitanicum, the observed non-satiated feeding on this alga suggest that an alternative mechanism could be responsible for the divergent responses. Previous studies on the influence of food nutritional composition on copepod feeding demonstrated that copepods increase their feeding effort in response to decreasing nutritional quality of food particles (Paffenhöfer \& Van Sant 1985, Libourel Houde \& Roman 1987). In this context, the non-satiated feeding on $A$. lusitanicum observed in the present experiments suggests that females obtained less nutrients or energy from the ingested amount of food than that needed to meet nutritional requirements for high egg production. As pointed out by Paffenhöfer \& Van Sant (1985), the actual amount of nitrogen assimilated by copepods rather than nitrogen availability should govern satiation. As indicated by the high nitrogen content, the nutritional quality of $A$. lusitanicum is not expected to be poor. Thus, a nutritional shortage could result from the interference of ingested toxins with digestive or assimilatory processes. Alternatively, an enhanced energy expenditure of females caused by ingested or assimilated toxins could account for energetic deficiencies

Assimilation depends largely on digestibility of food particles, digestive enzyme activities and assimilative capabilities of the copepod. A lower digestibility of the cellulose cell wall of Alexandrium lusitanicum likely did not influence digestive processes because Harvey et al. (1987) observed high assimilation in Calanus helgolandicus feeding on a non-toxic dinoflagellate. Additionally, several dinoflagellates have been reported to support egg production as high as that obtained from diatoms and flagellates (Ianora \& Poulet 
1993, Jónasdóttir 1994), indicating a high digestibility of dinoflagellates. Preconditioning and trophic history also affect a wide range of functions related to copepod nutrition, such as feeding selectivity, feeding rate and physiological responses (Donaghay 1988). Digestive enzyme activity in Acartia spp. has been shown to require a minimum of $2 \mathrm{~d}$ to acclimatize to changes in food ration and food type (e.g. Mayzaud et al. 1992). Accordingly, fecundity responds relatively quickly in Acartia spp. and achieves an equilibrium with ingested food in 1 to $3 \mathrm{~d}$ (Kiørboe et al. 1985, Tester \& Turner 1990). A similar response in egg production was observed at the beginning of the long-term experiment in females feeding on Rhodomonas baltica and, with delay, on A. lusitanicum. The persistence of reduced fecundity for several days on a diet of the toxic dinoflagellate, however, provides no evidence that low initial egg production rates were caused by affected digestive enzyme activities or assimilatory capabilities due to rearing of Acartia clausi on $R$. baltica prior to the experiments. Thus, neither low digestibility nor feeding history contributed to the observed nutritional deficiencies of $A$. clausi. The results obtained upon dietary exchange from $A$. lusitanicum to $R$. baltica further demonstrate that fecundity was affected adversely beyond direct exposure to the toxic alga. If a low nutritional content or low digestibility of A. lusitanicum had been responsible for reduced fecundity, then egg production should increase subsequently with the transfer to $R$. baltica, at least on Day 9 of incubation. Thus, ingested and accumulated toxins probably account for the nutritional deficiencies in females.

Saxitoxins are known to block sodium channels in cell membranes which are important for maintaining cell resting potential, generating electrical membrane signals or controlling hormonally triggered or metabolic processes (Strichartz \& Castle 1990). Therefore they could interfere with the control of enzyme secretion or active uptake of digested food compounds and consequently reduce the nutritional gain from ingested food. Alternatively, internal sequestering or detoxification of ingested toxins which may be an adaption of copepods (White 1981, Ives 1987) could cause an enhanced energy expenditure. Recovery of the physiological impairment after $3 \mathrm{~d}$ of incubation and the survival rates unaffected by Alexandrium lusitanicum indicate that females were able to cope with ingested toxins. If detoxification or internal sequestering accounts for lack of persistent adverse effects, then the processes to accomplish them could be energetically expensive and contribute to enhanced nutritional demands in females. Direct effects of saxitoxins on gonad maturation are also conceivable, but are unlikely to cause nutritional deficiencies. Therefore it is concluded that the reduced fecundity observed in
Acartia clausi primarily resulted from the interference of saxitoxins with digestive processes or energetic expenditure due to detoxification, or both mechanisms, which diminish the nutritional gain from ingested food. Consequently, females seem to compensate for this deficiency by increasing their feeding effort, as indicated by non-satiated feeding.

The present study further demonstrated that females of Acartia clausi were unable to convert the amount of food ingested in excess of the rate observed at $200 \mu \mathrm{g}$ $\mathrm{Cl}^{-1}$ into eggs. These results suggest that a critical concentration of the amount of toxins ingested or accumulated exists upon which no further nutrients or energy could be attained to support egg production. Interestingly, this corresponds well with satiation responses in toxin accumulation observed for copepods feeding on increasing concentrations of toxic Alexandrium spp. (Gosselin et al. 1989, Robineau et al. 1991). However, the mechanism that caused reduced fecundity in $A$. clausi as well as toxin dynamics in copepods are poorly understood and need further investigations in which respiration and egestion are monitored in addition to food uptake and secondary production.

Previous reports on zooplankton grazing interactions with toxic Alexandrium spp. unaffected demonstrate a wide variation of responses ranging from avoidance to unaffected food uptake (Tumer \& Tester 1997). However, the factors controlling variable feeding responses are largely unknown and remain uninvestigated. The high grazing rates of Acartia clausi on toxic Alexandrium lusitanicum observed in the present study suggest that saxitoxins do not act as allelochemical compounds against zooplankton grazing. Nevertheless, feeding on toxic Alexandrium spp. unaffected has important consequences. First, it emphasizes the high significance of copepods as toxin vectors in the marine food web because toxin accumulation is well demonstrated (e.g. White 1981). Second, ingestion of toxic food depresses fecundity of copepods, because there is a less efficient utilization of ingested food. The proposed mechanisms of toxin action on fecundity in copepods suggest that not only egg production but also growth of copepods may be reduced by phytoplankton that produce saxitoxins. Additionally, the utilization of non-toxic food ingested together with toxic algae may also be adversely affected, leading to a trophic mismatch and reduced secondary production.

Acknowledgements. I am grateful to Dr M. Elbrächter, who provided the inoculum of Alexandrium lusitanicum, and Drs L. Medlin and D. Crawford for correcting the English. I thank Dr J. T Turner and 2 unknown reviewers for helpful comments on the manuscript. The present study was supported by the Deutsche Forschungsgemeinschaft (DFG grant number BA 1508/1-1). This is Contribution No. 1503 of the Alfred Wegener Institute for Polar and Marine Research. 


\section{LITERATURF CITED}

Anderson DM, Cheng TPO (1988) Intracellular localization of saxitoxins in the dinoflagellate Gonyaulax tamarensis. $f$ Phycol 24:17-22

Anderson DM, Kulis DM, Sullivan JJ, Hall S, Lee C (1990) Dynamics and physiology of saxitoxin production by the dinoflagellates Alexandrium spp. Mar Biol 104:511-524

Bagoien F, Miranda A, Reguera B, Franco JM (1996) Effects of two paralytic shollfish toxin producing dinoflagellates on the pelagic harpacticoid copepod Euterpina acutifrons. Mar Biol 126:361-369

Berggreen U, Hansen B, Kiorboe T (1988) Food size spectra, ingestion and growth of the copepod Acartia tonsa during development: implications for determination of copepod production. Mar Biol 99:341-352

Boyer GL, Sullivan JJ, Andersen RJ, Harrison PJ, Taylor FJR (1987) Effects of nutrient limitation on toxin production and composition in the marine dinoflagellate Protogonyaulax tamarensis. Mar Biol 96:123-128

Checkley DM Jr (1980) The egg production of a marine planktonic copepod in relation to its food supply: laboratory studies. Limnol Oceanogr 25:430-446

Donaghay PL (1988) Role of temporal time scales of acclimation, food quality and trophic dominance in controlling the evolution of copepod feeding behavior Bull Mar Sci 43 $469-485$

Fiedler PC (1982) Zooplankton avoidance and reduced grazing responses to Gymnodinium splendens (Dinophyceae) Limnol Oceanogr 27:961-965

Fransz HG, Colebrook JM, Gamble JC, Krause M (1991) The zooplankton of the North Sea. Neth J Sea Res 28:1-52

Frost BW (1972) Effects of size and concentration of food particles on the feeding behavior of the marine planktonic copepod Calanus pacificus. Limnol Oceanogr 17:805-815

Gill CW, Harris RP (1987) Behavioural responses of the copepods Calanus helgolandicus and Temora longicornis to dinoflagellate diets. J Mar Biol Assoc UK 67:785-801

Gosselin S, Fortier L, Gagné JA (1989) Vulnerability of marine fish larvae to the toxic dinoflagellate Protogonyaulax tamarensis. Mar Ecol Prog Ser 57:1-10

Hallegraeff GM (1995) Harmful algal blooms: a global overview. In: Hallegraeff GM, Anderson DM, Cembella AD (eds) Manual on harmful marine microalgae. IOC manuals and guides No. 33. UNESCO, Paris, p $1-22$

Harvey HR, Eglington G, O'Hara SCM, Corner EDS (1987) Biotransformation and assimilation of dietary lipids by Calanus feeding on a dinoflagellate. Geochim Cosmochim Acta 51:3031-3040

Huntley M. Sykes P, Rohan S, Marin V (1986) Chemicallymediated rejection of dinoflagellate prey by the copepods Calanus pacificus and Paracalanus parvus: mechanism, occurrence and significance. Mar Ecol Prog Ser 28: $105-120$

Ianora A (1998) Copepod life history traits in subtemperate regions. J Mar Syst 15:337-349

Ianora A, Poulet SA (1993) Egg viability in the copepod Temora stylifera. Limnol Oceanogr 38:1615-1626

Ives JD (1985) The relationship between Gonyaulax tamarensis cell toxin levels and copepod ingestion rates. In: Anderson DM, White AW, Baden DG (eds) Toxic dinoflagellates. Elsevier, New York, p 413-418

Ives JD (1987) Possible mechanisms underlying copepod grazing responses to levels of toxicity in red tide dinoflagellates. J Exp Mar Biol Ecol 112:131-145

Jónasdóttir SH (1994) Effects of food quality on the reproductive success of Acartia tonsa and Acartia hudsonica: labo- ratory observations. Mar Biol 121:67-81

Kiøerboe T (1989) Phytoplankton growth rate and nitrogen content: implications for feeding and fecundity in a herbivorous copepod. Mar Ecol Prog Ser 55:229-234

Kiorboe T, Møhlenberg F, Hamburger K (1985) Bioenergetics of the planktonic copepod Acartia tonsa: relation between feeding, egg production and respiration, and composition of specific dynamic action. Mar Ecol Prog Ser 26:85-97

Kiørboe T, Sabatini M (1995) Scaljng of fecundity, growth and development in marine planktonic copepods. Mar Ecol Prog Ser 120:285-298

Klein Breteler WCM (1985) Fixation artifacts of phytoplankton in zooplankton grazing experiments. Hydrobiol Bull 19:13-19

Kleppel GS, Burkart CA (1995) Egg production and the nutritional environment of Acartia tonsa: the role of food quality in copepod nutrition. ICES J Mar Sci 52:297-304

Larsen NH, Moestrup $\varnothing$, Pedersen PM (1994) Scandinavian culture centre for algae \& protozoa. Dept of Phycology, Univ Copenhagen

Libourel Houde SE, Roman MR (1987) Effects of food quality on the functional ingestion response of the copepod Acartia tonsa. Mar Ecol Prog Ser 40:69-77

Mayzaud P, Roche-Mayzaud O, Razouls S (1992) Medium term time acclimation of feeding and digestive enzyme activity in marine copepods: influence of food concentration and copepod species. Mar Ecol Prog Ser 89:197-212

Nejstgaard JC, Solberg PT (1996) Repression of copepod feeding and fecundity by the toxic haptophyte Prymnesium patelliferum. Sarsia 81:339-344

Nielsen TG, Kiørboe T, Bjørnsen TK (1990) Effects of a Chrysochromulina polylepis subsurface bloom on the planktonic community. Mar Ecol Prog Ser 62:21-35

Nival P, Nival S (1976) Particle retention efficiencies of a herbivorous copepod, Acartia clausi (adult and copepodite stages): effects on grazing. Limnol Oceanogr 21:24-38

Oshima Y (1995) Post-column derivatization HPLC methods for paralytic shellfish poisons. In: Hallegraeff GM, Ander-

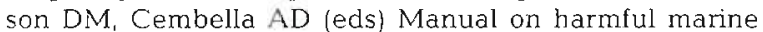
microalgae. IOC manuals and guides No. 33. UNESCO, Paris, p 81-94

Paffenhöfer GA, Van Sant KB (1985) The feeding response of a marine planktonic copepod to quantity and quality of particles. Mar Ecol Prog Ser 27:55-65

Plumley FG (1997) Marine algal toxins: Biochemistry, genetics, and molecular biology. Limnol Oceanogr 42: $1252-1264$

Robineau B, Fortier L, Gagné JA, Cembella AD (1991) Comparison of the response of five larval fish species to the toxic dinoflagellate Alexandrium excavatum (Braarud) Balech. J Exp Mar Biol Ecol 152:225-242

Shaw BA, Andersen RJ, Harrison PJ (1997) Feeding deterrent and toxicity effects of apo-fucoxanthinoids and phycotoxins on a marine copepod (Tigriopus californicus). Mar Biol 128:273-280

Smayda T (1997) Harmful algal blooms: their ecophysiology and generd relevance to phytoplankton blooms in the sea. Limnol Oceanogr 42:11.37-1.153

Sokal RR, Rohlf FJ (1995) Biometry, 3rd edn. Freeman and Company, New York

Stearns DE, Tester PA, Walker RL (1989) Diel changes in the egg production rate of Acartia tonsa (Copepoda, Cala noida) and related environmental factors in two estuaries Mar Ecol Prog Ser 52:7-16

Stoecker DK, Sanders NK (1985) Differential grazing by Acartia tonsa on a dinoflagellate and a tintinnid. J Plankton Res $7: 85-100$ 
Støttrup JG, Jensen J (1990) Influence of algal diet on feeding and egg-production of the calanoid copepod Acartia tonsa Dana. J Exp Mar Biol Ecol 141:87-105

Strichartz G, Castle N (1990) Pharmacology of marine toxins. Effects on membrane channels. In: Hall S, Strichartz G (eds) Marine toxins. Origin, structure, and molecular pharmacology. ACS Symp Ser 418:2-20

Teegarden GJ, Cembella AD (1996) Grazing of toxic dinoflagellates, Alexandrium spp., by adult copepods of coastal Maine: implications for the fate of paralytic shellfish toxins in marine food webs. J Exp Mar Biol Ecol 196:145-176

Tester PA, Turner JT (1990) How long does it take copepods to make eggs? J Exp Mar Biol Ecol 141:169-182

Turner JT, Tester PA (1997) Toxic marine phytoplankton, zooplankton grazers, and pelagic food webs. Limnol Oceanogr 42:1203-1214

Turner JT, Tester PA, Hansen PJ (1998) Interactions between toxic marine phytoplankton and metazoan and protistan grazers. In: Anderson DM, Cembella AD, Hallegraeff CM

Editorial responsibility: Otto Kinne (Editor), Oldendorf/Luhe, Germany (eds) Physiological ecology of harmful algal blooms. NATO ASI Series, Vol G 41. Springer-Verlag, Berlin, p $453-474$

Turriff N, Runge JA, Cembella AD (1995) Toxin accumulation and feeding behaviour of the planktonic copepod Calanus finmarchicus exposed to the red-tide dinoflagellate Alexandrium excavatum. Mar Biol 123:55-64

Uye SI (1981) Fecundity studies of neritic calanoid copepods Acartia clausi Giesbrecht and A. steueri Smirnov: a simple empirical model of daily egg production. J Exp Mar Biol Ecol 50:255-271

Uye SI, Takamatsu K (1990) Feeding interactions between planktonic copepods and red-tide flagellates from Japanese coastal waters. Mar Ecol Prog Ser 59:97-107

White AW (1981) Marine zooplankton can accumulate and retain dinoflagellate toxins and cause fish kills. Limnol Oceanogr 26:103-109

Wyatt T, Jenkinson IR (1997) Notes on Alexandrium population dynamics. J Plankton Res 19:551-575

Submitted: June 4, 1998; Accepted: September 16, 1998

Proofs received from author(s): November 20, 1998 